\title{
Research on the Innovative Strategy of Blended Teaching in Network Marketing in the Era of Big Data
}

\author{
Lei Liang*, Zhiyong Fan \\ School of Economics and Business Administration, Heilongjiang University, Harbin 150080, Heilongjiang Province, China \\ *Corresponding author: Lei Liang, lianglei@hlju.edu.cn

\begin{abstract}
Network Marketing is a practical professional compulsory course. With the advent of big data technology, a hybrid teaching model combining online and offline has emerged. Based on the analysis of the advantages of using a hybrid teaching model in Internet Marketing, this article comprehensively considers a variety of factors and put forward the innovative strategy of blended teaching in Network Marketing in the era of big data. This may provide new paths and methods for enhancing teaching effects, cultivating students' independent learning, and improving core literacy.
\end{abstract}

Keywords: Internet marketing; Blended teaching; Big data

Publication date: November 2021; Online publication: November 30, 2021

\section{Introduction}

With the rapid development of big data technology, human society has entered the era of big data. In the process of teaching network marketing in colleges and universities, the drawbacks of traditional teaching methods have emerged, and the accuracy, scientificity, and timeliness of education have attracted far more attention ${ }^{[1,2]}$. At present, many colleges and universities are gradually adjusting their teaching training programs according to their own development goals and actual needs as well as adopting various forms of curriculum practice teaching reform programs. The new crown pandemic at the end of 2019 forced major universities to passively accept new teaching models and gave educators a new understanding of online teaching, whereby they have gradually accepted and even taken the initiative to transform traditional offline teaching to an online and offline hybrid teaching ${ }^{[3]}$. Although the teaching mode has changed to a certain extent, in actual practice, the teaching effect cannot be fully guaranteed. In the teaching practice of Network Marketing in the era of big data, it is necessary for educators to make innovative exploration of teaching methods based on the particularities of the course and seek a more scientific education model to stimulate students' learning autonomy in an all-round way, thus improving their core literacy.

\section{Advantages of hybrid teaching in Network Marketing}

\subsection{Particularity of the Network Marketing course}

Network Marketing is a compulsory course for marketing majors and e-commerce majors. This course is a subject formed after the rapid development of internet technology during the Fourth Industrial Revolution. With the vigorous development of e-commerce companies, such as Alibaba, Taobao, and JD.com, the role of the Network Marketing course in supporting disciplines and professional development has become far more obvious. Network Marketing does not only include the theoretical basis of marketing, but also fully 
combine e-commerce technology and the internet on the basis of theory. Therefore, practical links must be added to the teaching process. On the one hand, students can master the basic theories in Network Marketing, and on the other hand, they can link those theories with the actual development of the internet. Traditional classroom teaching is generally taught by teachers ${ }^{[4]}$, even if a certain amount of practical training is added, the effect is far from meeting the course requirements. Students are not very active in learning, and their grasp of abstract knowledge is more at the theoretical level, which cannot be transformed into "real situations" ${ }^{[5]}$.

\subsection{Advantages of online teaching and offline teaching}

The advantage of traditional offline teaching is that the interaction between teachers and students is excellent. In classrooms, teachers are able to gauge students' expression in a timely manner, gain insights into their listening conditions, as well as timely adjust and determine their own rhythm to meet the individual needs of each student in a targeted manner to maximize the teaching effect.

The advantages of online teaching include two major aspects. First, there are abundant online teaching resources, and it provides flexibility in learning. The development of the internet allows the use of valuable curriculum resources from different schools, different regions, and different learning platforms for learning. By combing and integrating various resources in an all-round way, teachers are able to adopt more scientific teaching methods and teaching models to improve the classroom quality. Second, it is beneficial for quantitative evaluation and feedback ${ }^{[6]}$. The online teaching system is fully functional. In actual scenario, the system monitors and records the learning situation of the students, including pre-class preparations, participation by answering questions, after-class exercises and tests, etc. With all that, a complete learning report can be formed for each student. On the one hand, the data in those reports can be used as an overall judgment of the students' learning situation, and on the other hand, they assist teachers to promptly supervise and help the students to check for omissions and fill vacancies.

\subsection{Advantages of blended teaching}

Blended teaching is an "online" plus "offline" teaching that combines the advantages of online teaching and traditional teaching. The development of blended teaching is not for the purpose of using online platforms and building digital teaching resources, nor is it for realizing the diversity of teaching; rather, through the organic combination of the two teaching forms, the shallow learning of students can be led deeper, thus achieving the purpose of "real" education ${ }^{[7]}$. Teaching methods can include a combination of massive open online courses (MOOCs), flipped classroom, small-scale private online courses (SPOCs), and traditional offline teaching. In the teaching concept, students replace teachers as the leading factor and their initiative to explore knowledge replaces their passive learning ${ }^{[8]}$.

Blended teaching retains the advantages of the traditional teaching model. It incorporates the face-toface emotional injection of teachers and students into the concept of modern online teaching. It does not only promote teacher-student interaction, but also students' independent learning. This teaching mode can better mobilize students' subjective initiative, break the rules, explore and innovate independently in line with the students' individual needs, as well as change the teacher-led classroom to a student-led classroom. At the same time, as far as teachers are concerned, they need not follow the traditional teaching process anymore that focuses on the output of knowledge, but they can place more emphasis on designing the course process, organizing, and guiding students in autonomous learning. The teaching concept of blended teaching is an important manifestation of giving play to student-internal factors leading and teacher-external factors assisting, and it is also an important measure of supply-side structural reform to improve teaching 
efficiency ${ }^{[9]}$.

\section{Blended teaching strategies for Network Marketing in the era of big data}

\subsection{Shifting offline teaching to a student-led model}

(1) Teaching in the form of flipped classroom

The main contents of Network Marketing include network marketing positioning, website construction, network promotion, operation services, and network marketing management. The flipped classroom, which specifically includes group discussions, personal presentations, student evaluations, and teacher explanations, can be used ${ }^{[10]}$. Mutual evaluation by groups and studentstudent evaluation assist in the detection of students' mastery. By correcting students' misunderstandings in certain knowledge points, the explanation given by teachers would supplement students' knowledge loopholes. In addition, by setting aside 3-5 minutes for students to reflect on the lesson after the evaluation and uploading the contents of the evaluation and reflection onto the online platform may be beneficial.

(2) Condensing major concepts and key contents into different themes, and teach based on those themes rather than individual chapters

The course can be divided into different themes, and each theme would reflect a connection with the key contents in the course. This is conducive to students as they would be able to comprehensively grasp the knowledge system. At the same time, the various themes extracted would be assigned to students in the form of projects, allowing students to participate in scenario simulations and exercises, thus improving their ability to use important knowledge points and expand their innovation capabilities.

(3) Using mind maps to realize the visibility of the knowledge framework as well as important and difficult points

In the process of supplementing difficult and missing knowledge points, if students encounter knowledge points or knowledge systems that are relatively complex and difficult to understand, teachers can build a knowledge map or draw a mind map. In this way, the knowledge points or problem-solving ideas are visually guided; hence, students would have a clearer understanding of the mastery and application of knowledge points.

\subsection{Relying on big data technology for online teaching supervision}

(1) Assigning online preview tasks in advance

Pre-study materials should include national quality course resources of Network Marketing, the summary and record of key and difficult points in the course content, as well as the learning goals that students need to achieve. At the same time, task points can be set in videos, whereby students would be required to complete important knowledge-level tasks. Teachers should pay attention to students" "learning situation" in real time, accurately grasp their learning status, point out the deficiencies and bad habits in the learning process, as well as supervise the students' improvement.

(2) Uploading key and difficult topics on the platform

Combining the actual situation of the offline classroom, key and difficult points can be summarized into a number of topics, and the topics can be divided into general difficulty and practical application type extended questions prior to uploading them on the platform. Teachers can use methods such as "automatic assignment" to improve students' problem-solving efficiency. In this process, students 
would be required to upload their answers onto the platform, while the teachers would correct the answers and award credits to students who answered correctly. This targeted and hierarchical homework method helps to improve students' understanding of existing network marketing problems and their practical capabilities.

\subsection{Establishing a "pyramid" of learning evaluation}

The quantitative evaluation of students' learning conditions is carried out at different levels. Big data technology can be used to record students' learning situations and form a comprehensive report from that. The content of the report includes pre-class preparation time, task completion, class discussion and demonstration, student evaluation and after-class reflection, completion of homework after class, and completion of extended questions. Among them, the pre-class preparation time, the completion of task points, and the completion of homework after class comprehensively measure the "level of understanding" of the knowledge points. Class discussion and demonstration measure the "mastery" of knowledge points. Student evaluation reflects the "evaluation ability" of showing the situation to others. After being evaluated by others, self-reflection should be made in consideration of former evaluation, in order to make targeted inspections to fill in vacancies and to determine the students' "reflection ability". The extended questions and the online answering situation measure the "applicability" of the knowledge points. From all these, a learning evaluation "pyramid" can be formed, in which the hierarchy of the pyramid is from understanding, mastering, evaluation, reflection, to application, from low to high (Figure 1). Finally, by determining the weight of each level, the overall learning index of the student is measured as the student's usual grades. When determining the weightage of the usual grades and final exam results, the proportion of the usual grades should be strengthened, accounting for 50\%-60\% of the total grades as an example.

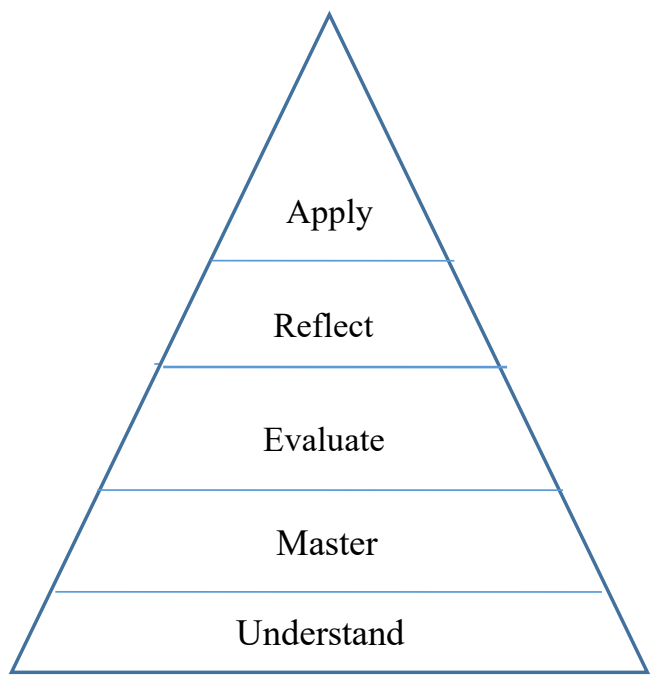

Figure 1. Pyramid of learning evaluation

\section{Conclusion}

Today, with the rapid development of big data, the issues of how to absorb the advantages of online and offline teaching methods, integrate multiple teaching methods to implement hybrid teaching, as well as improve the pertinence and scientific nature of the teaching of Network Marketing are significant. Educators in higher education institutions must constantly explore new educational methods, accept new educational concepts, and better apply the hybrid education in their teaching practice, so as to achieve the goal of 
encouraging students to actively explore the boundaries of knowledge and of theory guiding practice, thus promoting the improvement of students' comprehensive literacy. Blended teaching is a teaching mode that combines virtual and reality, comprehensively using high-quality online resources, flipped classroom, teaching data collection and analysis, as well as other favorable factors. On the one hand, it changes the knowledge output mode of being taught by teachers into the knowledge input mode of students' independent learning, while on the other hand, it helps teachers accurately grasp the learning situation of students, so that teachers would be able to modify their teaching contents and programs in a timely and targeted manner. Therefore, more emphasis should be on this kind of teaching mode. By boldly innovating in the teaching process while making full use of big data to explore an efficient teaching mode suitable for the information age would be beneficial to enhancing the comprehensive quality of students.

\section{Funding}

This study was supported by the Heilongjiang Province Educational Reform Project - Construction of the Cultivation System of Marketing Professionals' Entrepreneurship and Innovation Ability (Project Number: SJGY20200536) and Heilongjiang University's Key Educational Reform Project - Construction of the Cultivation System for Entrepreneurship and Innovation Capability of Marketing Majors (Project Number: 2020B41).

\section{Disclosure statement}

The authors declare that there is no conflict of interest.

\section{Author contributions}

Lei Liang conceived the idea of the study and wrote the paper. Zhiyong Fan was responsible for the research, data collection, and language modification.

\section{References}

[1] Xi J, 2017, The Report of the 19th National Congress of the Communist Party of China, Learning Press, Beijing, 24.

[2] Baoping R, 2019, Thoughts on the Reform of the Training System for Economics Professionals in the Era of Artificial Intelligence. Chinese University Teaching, (9).

[3] Jiang M, 2016, The Application of Flipped Classroom in the Teaching of Network Marketing Courses. Profession, (7): 97-99.

[4] Qu H, 2018, The Construction and Implementation of a Hybrid Teaching Model of Network Marketing Courses Based on I Ph.D. Tutoring Platform. Heilongjiang Science, (21): 13-15.

[5] Li X, 2016, The Key to the Implementation of Core Literacy Lies in Teachers' Transformation of Teaching Methods. Chinese Moral Education, 4(24): 6.

[6] Chen Z, 2020, The Theory and Practice of Online and Offline Integrated In-Depth Teaching in Colleges and Universities. Journal of Shenyang Normal University, (6): 97-104.

[7] Jiao W, Feng X, 2018, Research and Analysis of Blended Teaching Mode Based on Big Data. China Education Informationization (Higher Education and Vocational Education), (11): 38-41.

[8] Man X, 2020, Research on the Mixed Teaching Model of Higher Vocational English in the Era of Big Data. Modern Vocational Education, 4(02): 132-133. 
[9] Guo M, 2020, Exploration and Analysis of Upright Innovation in the Teaching of Ideological and Political Courses in Colleges and Universities in the Era of Big Data. International PR, (10): 64-65.

[10] Wang C, Tian X, Song Y, 2021, The Teaching and Learning of the Student-Centered "Internet Marketing" Course - The Practice of Flipped Classroom Using the I PhD and C Practice Platform. Modern Trade Industry, 42(24): 128-129. 